\title{
Retraction Note to: Effect of Temperature on the Dielectric Properties of Carbon Black-Filled Polyethylene Matrix Composites Below the Percolation Threshold
}

\author{
Soon-Gi Shin ${ }^{1} \cdot$ In-Kyu Kwon ${ }^{2}$
}

Published online: 19 February 2018

@ The Korean Institute of Metals and Materials 2018

Retraction Note to: Electronic Materials Letters, Vol. 7, No. 3 (2011), pp. 249-254

https://doi.org/10.1007/s13391-011-0913-1

The Editor-in-Chief and Editorial Board of Electronic Materials Letters have retracted this article [1] because it shows significant overlap with a publication by the same co-author without proper citation [2]. The contents of this article are therefore redundant. Neither of the authors responded to correspondence from the editor about this retraction.
The original article can be found online at https://doi.org/10.1007/ s13391-011-0913-1.

In-Kyu Kwon

kwonik@kangwon.ac.kr

1 Department of Advanced Materials Engineering, College of Samcheok, Kangwon National University, Samcheok-si, Gangwon 245-711, Korea

2 Department of Fire Protection Engineering, College of Samcheok, Kangwon National University, Samcheok-si, Gangwon 245-711, Korea

\section{References}

1. Shin, S.G., Kwon, I.K.: Electron. Mater. Lett. 7, 249 (2011). https://doi.org/10.1007/s13391-011-0913-1

2. Shin, S.G.: Kor. J. Mater. Res. 21, 196 (2011). https://doi. org/10.3740/MRSK.2011.21.4.196 